\title{
A Journal Ranking for the Ambitious Economist
}

\author{
Kristie M. Engemann and Howard J. Wall
}

\begin{abstract}
The authors devise an "ambition-adjusted" journal ranking based on citations from a short list of top general-interest journals in economics. Underlying this ranking is the notion that an ambitious economist wishes to be acknowledged not only in the highest reaches of the profession, but also outside his or her subfield. In addition to the conceptual advantages that they find in their ambition adjustment, they see two main practical advantages: greater transparency and a consistent treatment of subfields. They compare their 2008 ranking based on citations from 2001 to 2007 with a ranking for 2002 based on citations from 1995 to 2001. (JEL A11)
\end{abstract}

Federal Reserve Bank of St. Louis Review, May/June 2009, 91(3), pp. 127-39.

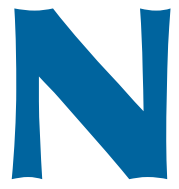
early every ranking of economics journals uses citations to measure and compare journals' research impact. ${ }^{1}$ Raw citation data, however, include a number of factors that generally are thought to mismeasure impact. For example, under the view that a citation in a top journal represents greater impact than a citation elsewhere, it is usual to weight citations according to their sources. The most common means by which weights are derived is the recursive procedure of Liebowitz and Palmer (1984) (henceforth LP), which handles the simultaneous determination of rank-adjusted weights and the ranks themselves.

We devise an alternative "ambition-adjusted" journal ranking for which the LP procedure is replaced by a simple rule that considers citations only from a short list of top general-interest journals in economics. ${ }^{2}$ Underlying this rule is the

1 A recent exception is Axarloglou and Theoharakis (2003), who survey members of the American Economic Association.

2 American Economic Review (AER), Econometrica, Economic Journal (ED), Journal of Political Economy (JPE), Quarterly Journal of Economics (QJE), Review of Economic Studies (REStud), and Review of Economics and Statistics (REStat). notion that a truly ambitious economist wishes to be acknowledged not only in the highest reaches of the profession, but also outside of his or her subfield. Thus, an ambitious economist also would like to publish his or her research in the journals that are recognized by the top general-interest outlets. In addition to the conceptual advantages that we find in our ambition adjustment, we see two main practical advantages: greater transparency and a consistent treatment of subfields.

The virtues of transparency are that the ranking has clear criteria for measuring the citations and these criteria are consistent over time. The LP procedure, in contrast, is largely a black box: It is not possible to see how sensitive the weights (and therefore the rankings) are to a variety of factors. The obvious objection to our rule is its blatant subjectivity. Our counter to this objection is to point out that the LP procedure, despite its sheen of objectivity, contains technical features that make it implicitly subjective.

First, as pointed out in Amir (2002), rankings derived using the LP procedure are not independent of the set of journals being considered: If a journal is added or subtracted from the set, the

Kristie M. Engemann is a senior research analyst and Howard J. Wall is a vice president and economist at the Federal Reserve Bank of St. Louis.

(C) 2009, The Federal Reserve Bank of St. Louis. The views expressed in this article are those of the author(s) and do not necessarily reflect the views of the Federal Reserve System, the Board of Governors, or the regional Federal Reserve Banks. Articles may be reprinted, reproduced, published, distributed, displayed, and transmitted in their entirety if copyright notice, author name(s), and full citation are included. Abstracts, synopses, and other derivative works may be made only with prior written permission of the Federal Reserve Bank of St. Louis. 
rankings of every other journal can be affected. It is for this reason that journals in subfields are treated differently. Significant numbers of citations come from journals that are outside the realm of pure economics (e.g., finance, law and economics, econometrics, and development), but the LP procedure does not measure all these citations in the same manner. For example, Amir attributes the extremely high rankings sometimes achieved by finance journals to data-handling steps within the LP procedure. On the other hand, for journals in subfields such as development, rankings are depressed by the exclusion of citations from sources other than purely economics journals.

Palacios-Huerta and Volij (2004) pointed out that a second source of implied subjectivity in the LP procedure is differences in reference intensity across journals. Specifically, they find a tendency for theory journals, which usually contain fewer citations than the average journal, to suffer from this reference-intensity bias. By convention, the typical theory paper provides fewer citations than the typical empirical paper, so journals publishing relatively more theory papers tend to see their rankings depressed.

An advantage of our blatantly subjective weighting rule is that it avoids the hidden subjectivity of the LP procedure by treating all subfields the same. First, the subfields are evaluated on equal footing as economics journals: i.e., journals in finance, law, and development are judged by their contributions to economics only. One might prefer a ranking that does otherwise, but this is the one we are interested in. Second, the cross-field reference-intensity bias is ameliorated by considering citations from general-interest journals only.

Before proceeding with our ranking of economics journals, we must point out that any ranking should be handled with a great deal of care when using it for decisionmaking. It would be a mistake, for example, to think that a journal ranking is anything like a definitive indicator of the relative quality of individual papers within the journals. First, any journal's citation distribution is heavily skewed by a small number of very successful papers, and even the highest-ranked journals have large numbers of papers that are cited rarely, if at all (Oswald, 2007; Wall, 2009). Put another way, citation distributions exhibit substantial overlap, meaning that (i) large shares of papers in the highest-ranked journals are cited less frequently than the typical paper in lowerranked journals; and, conversely, (ii) large shares of articles in low-ranked journals are cited more frequently than the typical paper in the highestranked journals.

\section{COMMON PRACTICES AND RECENT RANKINGS}

There is no such thing as the correct ranking of economics journals. Instead, there is a universe of rankings, each the result of a set of subjective decisions by its constructor. With the constructors' choices and criteria laid out as clearly as possible, the users of journal rankings would be able to choose the ranking, or rankings, that are the best reflection of the users' own judgment and situation. As outlined by Amir (2002), subjective decisions about which journals to include can inject bias through the objective LP procedure. In addition, every ranking is sensitive to the number of years of citation data, the choice of which publication years are to be included, and whether or not to include self-citations. Choices such as these are unavoidable. And any journal ranking, no matter how complicated or theoretically rigorous, cannot avoid being largely subjective. That said, there is much to be gained from a journal ranking that is as objective as possible and for which the many subjective choices are laid out so that the users of the ranking clearly understand the criteria by which the journals are being judged.

In an ideal world, the user will have chosen rankings on the basis of the criteria by which the rankings were derived and not on how closely they fit his or her priors. However, in addition to the usual human resistance to information that opposes one's preconceptions, users are also often hindered by a lack of transparency about the choices (and their consequences) underlying the various rankings. The onus, therefore, is on the constructors of the rankings to be as transparent as possible, so that the users need not depend on 
their priors when evaluating the many available rankings.

With this in mind, we lay out the most common practices developed over the years for constructing journal rankings. We assess our ranking along with a handful of the most prominent rankings of economics journals on the basis of their adherence to these practices (summarized in Table 1). Three of these rankings-Kalaitzidakis, Mamuneas, and Stengos (2003); Palacios-Huerta and Volij (2004); and Kodrzycki and Yu (2006)— are from the economics literature and are accompanied by analyses of the effects of the various choices on the rankings. The other two-the Thompson Reuters Journal Citation Reports (JCR) Impact Factor and the Institute for Scientific Information (ISI) Web of Science $h$-index-are commercially produced and widely available rankings covering a variety of disciplines. There has been little analysis of the reasonableness of their methods for ranking economics journals, however. ${ }^{3}$

\section{Control for Journal Size}

Most rankings control for journal size by dividing the number of adjusted citations by the number of articles in the journal, the number of adjusted pages, or even the number of characters. Whichever of these size measures is chosen, the purpose of controlling for journal size is to assess the journal on the basis of its research quality rather than its total impact combining quantity and quality. ${ }^{4}$ Of the five other rankings summarized in Table 1, all but one control for journal

3 Note that we have not included the several rankings provided on the RePEc website. The methodology used in those rankings is similar to what is used in the rankings that we discuss here. They deviate from usual practice in that their data include working paper series and the small set of journals that provide citation data for free. Given the heavy use of so-called gray literature and the biased set of citing journals, the website warns that the rankings are "experimental."

4 Our purpose is to rank journals on the basis of the quality of the research published within them, so a measure that controls for size is necessary to make the ranking useful for assessing the research quality of papers, people, or institutions. Others, however, might be interested in a ranking on the basis of total impact, whereby the quality of the research published within can be traded off for greater quantity. This is a perfectly valid question, but its answer does not turn out to be terribly useful for assessing journals' relative research quality. size. The ISI Web of Science produces a version of the $h$-index, which was proposed by Hirsch (2005) to measure the total impact of an individual researcher over the course of his or her career. Tracing a person's entire publication record from the most-cited to the least-cited, the $h$ th paper is the one for which each paper has been cited at least $h$ times. The intention of the $h$-index is to combine quality and quantity while reining in the effect that a small number of very successful papers would have on the average. In Wall (2009) the ranking according to the $h$-index was statistically indistinguishable from one according to total citations, indicating that $h$-indices are inappropriate for assessing journals' relative research quality. The other four rankings are, however, appropriate for this purpose.

The size control that we choose for our ranking is the number of articles. The primary reason for this choice is that the article is the unit of measurement by which the profession produces and summarizes research. ${ }^{5}$ Economists list articles on their curriculum vitae, not pages or characters. Generally speaking, an article represents an idea, and citations to an article are an acknowledgment of the impact of that idea. It matters little whether that idea is expressed in 20 pages or 10 . The reward for pages should not be imposed but should come through the effect that those pages have on an article's impact on the research of others. If a longer article means that an idea is more fully fleshed out, is somehow more important, or will have a greater impact, then this should be reflected in the number of citations it receives.

\section{Control for the Age of Articles}

Presumably, the most desirable journal ranking would reflect the most up-to-date measure of research quality that is feasible given the data constraints. As such, the information used to construct the ranking should restrict itself to papers published recently, although the definition of "recent"

5 In addition, the practical advantage of this size measure is its ease of use and ready availability. Because pages across journals differ a great deal in the number of words or characters they contain on average, a count of pages would have to be adjusted accordingly. An accounting of cross-journal differences in the average number of characters per article seems excessive. 


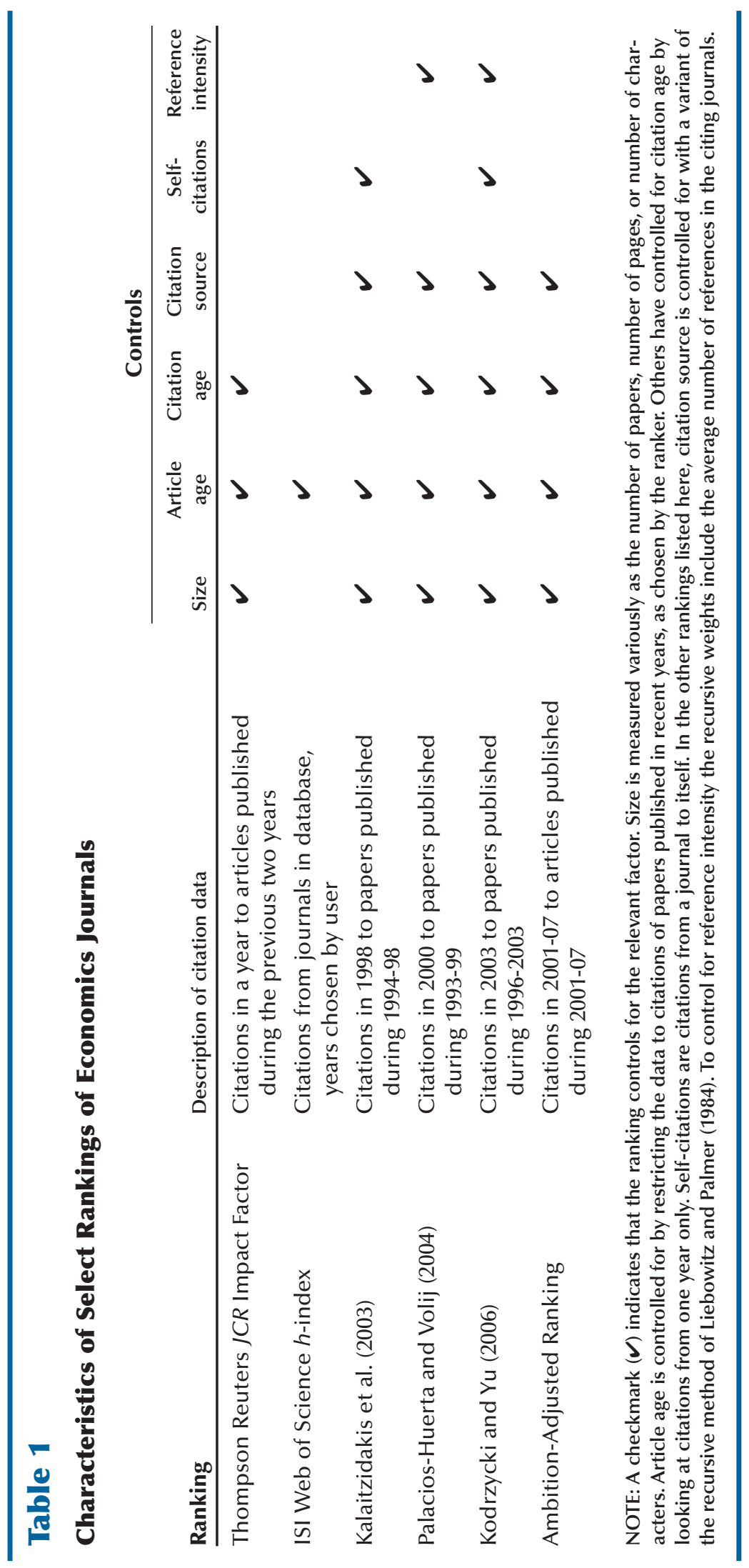


is open to interpretation. On the one hand, if one looks at citations to papers published in, say, only the previous year, the result would largely be noise: The various publication lags would preclude any paper's impact from being realized fully. Further, given the large differences in these lags across journals, the results would be severely biased. On the other hand, the further one goes back in time, the less relevant the data are to any journal's current research quality. Ideally, then, the data should go back just far enough to reflect some steady-state level of papers' impact while still being useful for measuring current quality.

Although all of the rankings listed in Table 1 restrict the age of articles, the Thompson Reuters JCR Impact Factor considers only papers published in the previous two years. Such a short time frame renders the information pretty useless for assessing economics journals, for which there are extremely large differences across journals in publication lags. ${ }^{6}$ The other rankings listed in the table use citation data on papers published over a five- to eight-year period. For our ranking we have elected to use citations to journals over the previous seven-year period.

\section{Control for the Age of Citations}

Because any ranking is necessarily backwardlooking, it should rely on the most recent expression of journal quality available, while at the same time having enough information to make the ranking meaningful and to minimize short-term fluctuations. To achieve this we look at citations made over a seven-year period to articles published during the same period. The standard practice has been to look only at citations during a single year to articles over some number of prior years. Because we are counting citations from a small number of journals, however, this would not be enough information to achieve our objectives.

\footnotetext{
${ }^{6}$ According to Garfield (2003), the two-year time frame was chosen in the early 1970s because it seemed appropriate for the two fields of primary interest: molecular biology and biochemistry. This ad hoc time frame thought appropriate for these two fields has remained the standard more than 35 years later across all fields in the hard sciences, the social sciences, humanities, etc.
}

\section{Adjust for Citation Source}

As we outlined in our introduction, the most important difference between our ranking and others is in its treatment of citation sources. While we agree with the premise that citation source matters, we do not agree that the most appropriate way to handle the issue is the application of the LP procedure. Therefore, we replace the LP procedure with a simple rule: We count only citations from the top seven general-interest journals as determined by the total number of non-selfcitations per article they received in 2001-07.

\section{Exclude Self-Citations}

To ensure that a journal's impact reaches outside its perhaps limited circle of authors, selfcitations-that is, citations from papers in a journal to other papers in the same journal-are usually excluded when ranking economics journals. Although self-citations are not necessarily bad things, the practice has been to err on the side of caution and eliminate them from every journal's citation count. In our ranking, however, selfcitations are relevant only for the seven generalinterest journals, which could put them at a severe disadvantage relative to the rest of the journals. Further, it's conceivable that the rate of bad selfcitations differs a lot across the seven generalinterest journals. If so, then a blanket elimination of self-citations would be unfair to some of the journals with relatively few bad self-citations and would affect the ranking within this subset of journals.

Because of our concerns, we do not control for journal self-citations in our ranking. Admittedly, this is a judgment call because it is not possible to know for each journal how many of the selfcitations should be eliminated. We have, therefore, also produced a ranking that eliminates all selfcitations. As we show, this affects the ordering, but not the membership, of the top five journals. We leave it to the user to choose between the two alternative rankings.

\section{Control for Reference Intensity}

As shown by Palacios-Huerta and Volij (2004), journals can differ a great deal in the average number of citations given by their papers. These 


\section{Table 2}

\section{Reference Intensities}

\begin{tabular}{lcc} 
& $\mathbf{2 0 0 0}$ & $\mathbf{2 0 0 7}$ \\
\hline American Economic Review & 1.0 & 1.0 \\
Econometrica & 0.6 & 0.9 \\
Economic Journal & 0.5 & 1.0 \\
Journal of Political Economy & 0.6 & 1.0 \\
Quarterly Journal of Economics & 0.9 & 1.2 \\
Review of Economics and Statistics & 0.5 & 1.0 \\
Review of Economic Studies & 0.8 & 1.0
\end{tabular}

NOTE: Reference intensity is the average number of references per article relative to that of the American Economic Review. The numbers for 2000 are from Palacios-Huerta and Volij (2004).

differences reflect the variety of attitudes and traditions across fields, and there is a tendency for the rankings of theory journals to suffer as a result. For example, according to Palacios-Huerta and Volij, in 2000 the average article in the Journal of Monetary Economics contained 80 percent more references than did the average across all articles, which would result in an upward bias for the rankings of journals that are cited relatively heavily in that journal. Similarly, the average articles in the $A E R$ and the QJE contained, respectively, 70 percent and 50 percent more references than average. At the other end, the average articles in the Journal of Business and Economic Statistics, the AER Papers and Proceedings, and the International Journal of Game Theory each contained only 40 percent of the average number of references.

The potential problem with differences in reference intensity is that journals receiving disproportionate numbers of citations from journals with high reference intensities would have an artificially high ranking. In effect, high reference intensity gives some journals more votes about the quality of research published in other journals. Indeed, as reported in Table 2, the differences in reference intensity across our seven generalinterest journals were substantial in 2000. For 2007, however, using our citation dataset, which is more limiting than that of Palacios-Huerta and Volij (2004), reference intensities differed very little. ${ }^{7}$ Further, adjusting for the differences that did exist would have had very little effect on our ranking. ${ }^{8}$ Therefore, in the interest of simplicity and transparency, our ranking does not take differences in reference intensity into account.

\section{AN AMBITION-ADJUSTED JOURNAL RANKING}

We start with a list of 69 journals that does not include non-refereed or invited-paper journals (the Journal of Economic Literature, Brookings Papers on Economic Activity, and the Journal of Economic Perspectives). We treat the May Papers and Proceedings issue of the AER separately from the rest of the journal because, as shown below, it is much less selective than the rest of the AER. The list is by no means complete, but we think that it contains most, if not all, journals that would rank in the top 50 if we considered the universe of economics journals. Nonetheless, an advantage of our ranking is that, because it is independent of the set of included journals, it is very easy to determine the position of any excluded journal because one needs only to navigate the ISI Web of Science website to obtain the data for the journal. ${ }^{9}$

We looked at all citations during 2001-07 from articles in the seven general-interest journals to articles in each of the 69 journals. Note that, using the Web of Science terminology, articles do not include proceedings, editorial material, book reviews, corrections, reviews, meeting abstracts,

\footnotetext{
7 One reason that Palacios-Huerta and Volij (2004) found larger differences in reference intensity is because they considered all papers published in a journal, including short papers, comments, and non-refereed articles. Our dataset, on the other hand, includes only regular refereed articles.

${ }^{8}$ If citations to journals for which the QJE tended to overcite were adjusted to the citation tendencies across the other general-interest journals, the rankings of the affected journals would be nearly identical.

9 From the main page, search by the journal name using the default time span of "all years." Refine the results to include articles from 2001-07 only. Create a citation report, view the citing articles, and refine to exclude all but articles and anything from years other than 2001-07. Click "Analyze results" and rank by source title, analyze up to 100,000 records, show the top 500 results with a threshold of 1 , and sort by selected field. Select the seven general-interest journals and view the record, yielding the number of citations to the journal from these sources.
} 
biographical items, software reviews, letters, news items, and reprints. ${ }^{10}$ Also note that the citations are all those that were in the database as of the day that the data were collected: November 13, 2008.

Table 3 includes the number of articles, the number of adjusted cites (adjusted to include only those from the seven general-interest journals), the impact factor, and the relative impact. The impact factor is simply the number of adjusted cites per article, whereas the relative impact divides this by the impact factor of the AER. It's worth pointing out once again that one should handle this and any other journal ranking with care. Saying that "the average article in journal A received more citations than the average article in journal B" is a long way from saying "an article in journal A is better than an article in journal B."

There are some general results apparent from Table 3. First, the five top-ranked journals-QJE, $J P E$, Econometrica, AER, and REStud-are clearly separate from the rest: The fifth-ranked REStud is indistinguishable from the $A E R$ while the sixthranked Journal of Labor Economics has 55 percent of the average impact of the $A E R$. Further, within the top five, the QJE and JPE are clearly distinguishable from the rest, with the QJE well ahead of the JPE. Specifically, the QJE and JPE had, respectively, 78 percent and 41 percent greater impact per article than the $A E R$.

Second, the journals ranked sixth through ninth, with relative impacts ranging from the aforementioned 0.55 for the Journal of Labor Economics to 0.40 for the Economic Journal, are clearly separate from the remainder of the list. From the tenth-ranked journal on down, however, there are no obvious groupings of journals in that relative impact declines fairly continuously.

Several journals introduced in recent years have been relatively successful at generating citations. Most prominently, the Journal of Economic Growth, which began publishing in 1996 and for which citation data are available starting in 1999, is the seventh-ranked journal. It is among the group ranked sixth through ninth that is not quite the elite but is clearly separate from the next tier. The 18th-ranked Review of Economic Dynamics,

\footnotetext{
${ }^{10}$ The AER Papers and Proceedings is the exception to this.
}

which began publishing in 1998 and for which citation data are available from 2001, has been another very successful newcomer. The Journal of the European Economic Association has established itself in an even shorter period of time. It began publishing in 2003 and is ranked a very respectable 31st.

At this stage an alert reader with strong priors will, perhaps, question our ranking on the basis of its inclusion of self-citations. After all, the JPE and QJE, our two top-ranked journals, are considered (at least anecdotally) to have a publication bias toward adherents of the perceived worldviews of their home institutions. If this supposition is true, then their rankings might be inflated by the inclusion of self-citations. As we show in Table 4, however, the supposition is false.

The first column of numbers in Table 4 gives the raw number of self-citations, while the second column gives self-citations as a percentage of total citations from the seven reference journals. The most important number for each journal is in the third column, the self-citation rate, which is the average number of self-citations per article. Among the top five journals, the most notable differences are that the self-cites are relatively rare in the REStud, whereas the QJE and Econometrica have the highest self-citation rates. The effect of eliminating self-citations is to slightly reshuffle the top five, without any effect on the aforementioned relative positions of the QJE and JPE. The most notable effect that the exclusion of self-citations has is on the rankings of the $E J$, which drops from 9th to 17 th place.

As outlined in the previous section, we think that the negatives from eliminating self-citations outweigh the positives. In the end, however, doing so would have relatively little effect on the resulting ranking. Nevertheless, the reader has both versions from which to choose.

\section{TRENDS IN AMBITION-ADJUSTED RANKINGS}

Table 5 reports the ambition-adjusted ranking for 2002, which is based on citations in 1995-2001 for articles published during the same period. 
Table 3

Ambition-Adjusted Journal Ranking, 2008

\begin{tabular}{|c|c|c|c|c|c|}
\hline & Journal & Articles & Adjusted cites & Impact factor & Relative impact \\
\hline 1 & Quarterly Journal of Economics & 283 & 470 & 1.66 & 1.78 \\
\hline 2 & J of Political Economy & 296 & 390 & 1.32 & 1.41 \\
\hline 3 & Econometrica & 420 & 442 & 1.05 & 1.13 \\
\hline 4 & American Economic Review & 644 & 601 & 0.93 & 1.00 \\
\hline 5 & Review of Economic Studies & 292 & 271 & 0.93 & 0.99 \\
\hline 6 & J of Labor Economics & 201 & 104 & 0.52 & 0.55 \\
\hline 7 & J of Economic Growth (1999) & 87 & 39 & 0.45 & 0.48 \\
\hline 8 & Review of Economics \& Statistics & 456 & 192 & 0.42 & 0.45 \\
\hline 9 & Economic Journal & 498 & 185 & 0.37 & 0.40 \\
\hline 10 & American Economic Review P \& P & 592 & 179 & 0.30 & 0.32 \\
\hline 11 & International Economic Review & 336 & 95 & 0.28 & 0.30 \\
\hline 12 & J of Monetary Economics & 449 & 121 & 0.27 & 0.29 \\
\hline 13 & Rand Journal of Economics & 285 & 73 & 0.26 & 0.27 \\
\hline 14 & J of International Economics & 400 & 100 & 0.25 & 0.27 \\
\hline 15 & J of Law \& Economics & 169 & 42 & 0.25 & 0.27 \\
\hline 16 & J of Economic Theory & 713 & 175 & 0.25 & 0.26 \\
\hline 17 & J of Public Economics & 606 & 133 & 0.22 & 0.24 \\
\hline 18 & Review of Economic Dynamics (2001) & 234 & 48 & 0.21 & 0.22 \\
\hline 19 & J of Business \& Economic Statistics & 250 & 50 & 0.20 & 0.21 \\
\hline 20 & J of Finance & 589 & 117 & 0.20 & 0.21 \\
\hline 21 & Games \& Economic Behavior & 492 & 93 & 0.19 & 0.20 \\
\hline 22 & J of Econometrics & 601 & 104 & 0.17 & 0.19 \\
\hline 23 & European Economic Review & 482 & 77 & 0.16 & 0.17 \\
\hline 24 & Review of Financial Studies & 289 & 43 & 0.15 & 0.16 \\
\hline 25 & J of Financial Economics & 496 & 70 & 0.14 & 0.15 \\
\hline 26 & J of Industrial Economics & 166 & 23 & 0.14 & 0.15 \\
\hline 27 & J of Applied Econometrics & 258 & 35 & 0.14 & 0.15 \\
\hline 28 & J of Human Resources & 224 & 29 & 0.13 & 0.14 \\
\hline 29 & J of Law, Economics \& Organization & 146 & 18 & 0.12 & 0.13 \\
\hline 30 & J of Development Economics & 461 & 55 & 0.12 & 0.13 \\
\hline 31 & J of the European Econ Assoc (2005) & 80 & 9 & 0.11 & 0.12 \\
\hline 32 & J of Urban Economics & 350 & 37 & 0.11 & 0.11 \\
\hline 33 & Scandinavian Journal of Economics & 227 & 23 & 0.10 & 0.11 \\
\hline 34 & Oxford Economic Papers & 229 & 21 & 0.09 & 0.10 \\
\hline 35 & J of Economic Behavior \& Org & 508 & 44 & 0.09 & 0.09 \\
\hline 36 & Economica & 234 & 20 & 0.09 & 0.09 \\
\hline
\end{tabular}




\section{Table 3, cont'd}

\section{Ambition-Adjusted Journal Ranking, 2008}

\begin{tabular}{|c|c|c|c|c|c|}
\hline & Journal & Articles & Adjusted cites & Impact factor & Relative impact \\
\hline 37 & J of Risk \& Uncertainty & 167 & 14 & 0.08 & 0.09 \\
\hline 38 & Oxford Bulletin of Econ \& Statistics & 229 & 18 & 0.08 & 0.08 \\
\hline 39 & Macroeconomic Dynamics (1998) & 177 & 13 & 0.07 & 0.08 \\
\hline 40 & Economic Inquiry & 360 & 26 & 0.07 & 0.08 \\
\hline 41 & Economic Theory & 651 & 46 & 0.07 & 0.08 \\
\hline 42 & Econometric Theory & 356 & 25 & 0.07 & 0.08 \\
\hline 43 & J of Money, Credit \& Banking & 390 & 26 & 0.07 & 0.07 \\
\hline 44 & Canadian Journal of Economics & 349 & 22 & 0.06 & 0.07 \\
\hline 45 & J of Economic Geography (2002) & 106 & 6 & 0.06 & 0.06 \\
\hline 46 & J of Business & 302 & 17 & 0.06 & 0.06 \\
\hline 47 & J of Economic History & 214 & 12 & 0.06 & 0.06 \\
\hline 48 & J of Health Economics & 375 & 20 & 0.05 & 0.06 \\
\hline 49 & J of Economic Dynamics \& Control & 636 & 32 & 0.05 & 0.05 \\
\hline 50 & International J of Industrial Org & 441 & 22 & 0.05 & 0.05 \\
\hline 51 & J of International Money \& Finance & 304 & 15 & 0.05 & 0.05 \\
\hline 52 & J of Financial \& Quantitative Analysis & 234 & 10 & 0.04 & 0.05 \\
\hline 53 & Regional Science \& Urban Economics & 219 & 9 & 0.04 & 0.04 \\
\hline 54 & Economics Letters & 1,736 & 70 & 0.04 & 0.04 \\
\hline 55 & J of Mathematical Economics & 280 & 11 & 0.04 & 0.04 \\
\hline 56 & J of Policy Analysis \& Management & 239 & 8 & 0.03 & 0.04 \\
\hline 57 & J of Environ Econ \& Management & 341 & 10 & 0.03 & 0.03 \\
\hline 58 & National Tax Journal & 205 & 6 & 0.03 & 0.03 \\
\hline 59 & Public Choice & 555 & 13 & 0.02 & 0.03 \\
\hline 60 & J of Regional Science & 201 & 4 & 0.02 & 0.02 \\
\hline 61 & J of Macroeconomics & 235 & 3 & 0.01 & 0.01 \\
\hline 62 & Papers in Regional Science & 172 & 2 & 0.01 & 0.01 \\
\hline 63 & Southern Economic Journal & 370 & 4 & 0.01 & 0.01 \\
\hline 64 & J of Banking \& Finance & 703 & 7 & 0.01 & 0.01 \\
\hline 65 & Economic History Review & 110 & 1 & 0.01 & 0.01 \\
\hline 66 & Annals of Regional Science & 241 & 2 & 0.01 & 0.01 \\
\hline 67 & Contemporary Economic Policy & 189 & 1 & 0.01 & 0.01 \\
\hline 68 & Applied Economics & 1,459 & 7 & 0.00 & 0.01 \\
\hline 69 & J of Forecasting & 225 & 1 & 0.00 & 0.00 \\
\hline
\end{tabular}

NOTE: The impact factor is the number of adjusted citations per article. A relative impact is the impact factor relative to that of the American Economic Review. Italics indicate a journal for which data are incomplete for some years between 1995 and 2007 . For newer journals, the years that the citation data begin are in parentheses. The Journal of Business ceased operation at the end of 2006. 
Table 4

Ambition-Adjusted Journal Ranking Excluding Self-Citations, 2008

\begin{tabular}{|c|c|c|c|c|c|c|}
\hline & Journal & $\begin{array}{c}\text { Self- } \\
\text { citations }\end{array}$ & $\begin{array}{c}\text { Percent } \\
\text { self-citations }\end{array}$ & $\begin{array}{c}\text { Self- } \\
\text { citation rate }\end{array}$ & $\begin{array}{r}\text { Relative } \\
\text { impact }\end{array}$ & $\begin{array}{l}\text { Change } \\
\text { in rank }\end{array}$ \\
\hline 1 & Quarterly Journal of Economics & 128 & 27.2 & 0.45 & 1.96 & 0 \\
\hline 2 & J of Political Economy & 70 & 17.9 & 0.24 & 1.75 & 0 \\
\hline 3 & Review of Economic Studies & 56 & 20.7 & 0.19 & 1.19 & 2 \\
\hline 4 & Econometrica & 152 & 34.4 & 0.36 & 1.12 & -1 \\
\hline 5 & American Economic Review & 204 & 33.9 & 0.32 & 1.00 & -1 \\
\hline 6 & J of Labor Economics & & & & 0.84 & 0 \\
\hline 7 & J of Economic Growth (1999) & & & & 0.73 & 0 \\
\hline 8 & American Economic Review P \& P & & & & 0.49 & 2 \\
\hline 9 & Review of Economics \& Statistics & 58 & 30.2 & 0.13 & 0.48 & -1 \\
\hline 10 & International Economic Review & & & & 0.46 & 1 \\
\hline 11 & J of Monetary Economics & & & & 0.44 & 1 \\
\hline 12 & Rand Journal of Economics & & & & 0.42 & 1 \\
\hline 13 & J of International Economics & & & & 0.41 & 1 \\
\hline 14 & J of Law \& Economics & & & & 0.40 & 1 \\
\hline 15 & J of Economic Theory & & & & 0.40 & 1 \\
\hline 16 & J of Public Economics & & & & 0.36 & 1 \\
\hline 17 & Economic Journal & 77 & 41.6 & 0.15 & 0.35 & -8 \\
\hline 18 & Review of Economic Dynamics (2001) & & & & 0.33 & 0 \\
\hline 19 & J of Business \& Economic Statistics & & & & 0.32 & 0 \\
\hline 20 & J of Finance & & & & 0.32 & 0 \\
\hline
\end{tabular}

NOTE: Citations are adjusted to exclude citations from the journal to articles in the same journal. The percent of self-citations is selfcitations relative to total citations, while the self-citation rate is the number of self-citations per article. A journal's relative impact is its impact factor relative to that of the American Economic Review. Italics indicate a journal for which data are incomplete for some years between 1995 and 2007. For newer journals, the years that the citation data begin are in parentheses. The change in rank is the difference between Tables 3 and 4.

The table also reports the change in rank between 2002 and 2008 for each journal. The first thing to note is the stability at the very top of the ranking, as the top six journals are exactly the same for the two periods. Beyond that, however, there was a great deal of movement for some journals. ${ }^{11}$

As mentioned earlier, because several new journals placed relatively well in the 2008 ranking, there will necessarily be some movement across the board as journals are bumped down the ranking by the entrants, none of which was ranked

11 The Spearman rank-correlation coefficient for the 2002 and 2008 rankings is 0.79 . higher than 50th in 2002. In addition to the new journals, several journals made notable strides between 2002 and 2008. The Journal of Law and Economics, for example, moved from the 30th position in 2002 to the 15 th position in 2008, while the Journal of Financial Economics, Journal of Development Economics, and Journal of Industrial Economics all moved into the top 30.

On the other hand, some journals experienced significant downward movement in their ranking. Three-the Journal of Monetary Economics, Rand Journal of Economics, and Journal of Human Resources-fell out of the top ten. Although the first two of these fell by only five positions, the 


\section{Table 5}

\section{Change in Journal Ranking, 2002 to 2008}

\begin{tabular}{|c|c|c|c|c|c|}
\hline Journal & $\begin{array}{c}\text { Rank } \\
2002 \\
\end{array}$ & $\begin{array}{c}\text { Change } \\
2002 \\
\text { to } 2008\end{array}$ & Journal & $\begin{array}{c}\text { Rank } \\
2002\end{array}$ & $\begin{array}{c}\text { Change } \\
2002 \\
\text { to } 2008 \\
\end{array}$ \\
\hline Quarterly Journal of Economics & 1 & 0 & J of Urban Economics & 36 & 4 \\
\hline J of Political Economy & 2 & 0 & J of Business & 37 & -9 \\
\hline Econometrica & 3 & 0 & J of Health Economics & 38 & -10 \\
\hline American Economic Review & 4 & 0 & National Tax Journal & 39 & -19 \\
\hline Review of Economic Studies & 5 & 0 & J of Development Economics & 40 & 10 \\
\hline J of Labor Economics & 6 & 0 & Regional Science \& Urban Economics & 41 & -12 \\
\hline J of Monetary Economics & 7 & -5 & J of Industrial Economics & 42 & 16 \\
\hline Rand Journal of Economics & 8 & -5 & J of Economic Behavior \& Org & 43 & 8 \\
\hline Review of Economics \& Statistics & 9 & 1 & Scandinavian Journal of Economics & 44 & 11 \\
\hline J of Human Resources & 10 & -18 & J of Policy Analysis \& Management & 45 & -11 \\
\hline Economic Journal & 11 & 2 & Canadian Journal of Economics & 46 & 2 \\
\hline International Economic Review & 12 & 1 & J of Economic History & 47 & 0 \\
\hline J of Economic Theory & 13 & -3 & J of Risk \& Uncertainty & 48 & 11 \\
\hline American Economic Review P \& P & 14 & 4 & International J of Industrial Org & 49 & -1 \\
\hline Games \& Economic Behavior & 15 & -6 & J of Economic Growth (1999) & 50 & 43 \\
\hline J of Money, Credit \& Banking & 16 & -27 & J of International Money \& Finance & 51 & 0 \\
\hline J of Business \& Economic Statistics & 17 & -2 & Economics Letters & 52 & -2 \\
\hline J of Public Economics & 18 & 1 & J of Mathematical Economics & 53 & -2 \\
\hline J of Econometrics & 19 & -3 & J of Financial \& Quantitative Analysis & 54 & 2 \\
\hline European Economic Review & 20 & -3 & Public Choice & 55 & -4 \\
\hline J of International Economics & 21 & 7 & Southern Economic Journal & 56 & -7 \\
\hline J of Finance & 22 & 2 & Macroeconomic Dynamics (1998) & 57 & 18 \\
\hline Review of Financial Studies & 23 & -1 & Contemporary Economic Policy & 58 & -9 \\
\hline J of Applied Econometrics & 24 & -3 & J of Macroeconomics & 59 & -2 \\
\hline J of Law, Economics \& Organization & 25 & -4 & J of Banking \& Finance & 60 & -4 \\
\hline Econometric Theory & 26 & -16 & Economic History Review & 61 & -4 \\
\hline Economica & 27 & -9 & Papers in Regional Science & 62 & 0 \\
\hline Economic Theory & 28 & -13 & Applied Economics & 63 & -5 \\
\hline J of Economic Dynamics \& Control & 29 & -20 & J of Forecasting & 64 & -5 \\
\hline J of Law \& Economics & 30 & 15 & J of Regional Science & 65 & 5 \\
\hline Economic Inquiry & 31 & -9 & Annals of Regional Science & 66 & 0 \\
\hline J of Financial Economics & 32 & 7 & Review of Economic Dynamics (2001) & 67 & 49 \\
\hline J of Environ Econ \& Management & 33 & -24 & J of the European Econ Assoc (2005) & 68 & 37 \\
\hline Oxford Economic Papers & 34 & 0 & J of Economic Geography (2002) & 69 & 24 \\
\hline Oxford Bulletin of Econ \& Statistics & 35 & -3 & & & \\
\hline
\end{tabular}


Journal of Human Resources fell from the tenth all the way to the 28th position. Still, no journal fell by as much as the Journal of Money, Credit, and Banking, which was the 16th-ranked journal in 2002 but the 43rd-ranked one in 2008. Finally, three journals-the Journal of Economic Dynamics and Control, Economic Theory, and Econometric Theory-dropped from among the 20th- to 30thranked journals to outside the top 40. Although it is well beyond our present scope to explain the movement in journal ranking over time, at least some of the movement appears to have been due to the entrant journals. The most successful of the entrants can be described in general terms as macro journals, and their effects on the positions of incumbent journals in the field do not seem to have been nugatory.

\section{SUMMARY AND CONCLUSION}

There is no such thing as "the" correct journal ranking. All journal rankings, even those using the seemingly objective LP procedure, are sensitive to the subjective decisions of their constructors. Whether it's the set of journals to consider, the ages of citations and articles to allow, or the question of including self-citations, a ranking is the outcome of many judgment calls. What would be most useful for the profession is an array of rankings for which the judgment calls are clearly laid out so that users can choose among them. Ideally, decisions of this sort would be made on the basis of the criteria by which the rankings are constructed, rather than whether or not the outcome of the ranking satisfied one's imperfectly informed priors. Clear expressions of the inputs and judgments would be of great use in achieving this ideal.

Our ranking is a contribution to this ideal scenario. We have chosen a clear rule for which citations to use and have laid out exactly what we have done with our citation data to obtain our ranking. Some of our judgments, such as not controlling for reference intensity, are a nod to transparency and ease of use over precision. Also, by including self-citations we have chosen one imperfect metric over another purely on the grounds of our own judgment. On the other hand, we have shown that the effects that these judgments have on our ranking are not major. Finally, given that Wall (2009) has shown that large mental error bands should be used with any journal ranking, we would have been comfortable with even more imprecision than we have allowed.

\section{REFERENCES}

Amir, Rabah. "Impact-Adjusted Citations as a Measure of Journal Quality.” CORE Discussion Paper 2002/74, Université Catholique de Louvain, December 2002.

Axarloglou, Kostas and Theoharakis, Vasilis. "Diversity in Economics: An Analysis of Journal Quality Perceptions." Journal of the European Economic Association, December 2003, 1(6), pp. 1402-23.

Garfield, Eugene. "The Meaning of the Impact Factor." Revista Internacional de Psicología Clínica y de la Salud/International Journal of Clinical and Health Psychology, 2003, 3(2), pp. 363-69.

Hirsch, Jorge E. “An Index to Quantify an Individual's Scientific Research Output." Proceedings of the National Academy of Sciences, November 2005, 102(46), pp. 16569-72.

Kalaitzidakis, Pantelis; Mamuneas, Theofanis P. and Stengos, Thanasis. "Rankings of Academic Journals and Institutions in Economics." Journal of the European Economic Association, December 2003, 1(6), pp. 1346-66.

Kodrzycki, Yolanda K. and Yu, Pingkang. "New Approaches to Ranking Economics Journals." Contributions to Economic Analysis and Policy, 2006, 5(1), Article 24.

Liebowitz, Stanley J. and Palmer, John P. “Assessing the Relative Impacts of Economics Journals." Journal of Economic Literature, March 1984, 22(1), pp. 77-88.

Oswald, Andrew J. "An Examination of the Reliability of Prestigious Scholarly Journals: Evidence and Implications for Decision-Makers.” Economica, February 2007, 74(293), pp. 21-31. 
Palacios-Huerta, Ignacio and Volij, Oscar. "The Measurement of Intellectual Influence."

Econometrica, May 2004, 72(3), pp. 963-77.

Wall, Howard J. "Journal Rankings in Economics: Handle with Care.” Working Paper No. 2009-014A, Federal Reserve Bank of St. Louis, April 2009;

http://research.stlouisfed.org/wp/2009-014.pdf. 
